\title{
INTERPRETACIÓN \\ DE LA CONSTITUCIÓN, ESTADO AUTONÓMICO Y TRIBUNAL CONSTITUCIONAL
}

\author{
Ignacio TORRES MURO \\ Cuerpo de Letrados del Tribunal Constitucional \\ Departamento de Derecho Constitucional \\ Facultad de Derecho \\ Universidad Complutense de Madrid \\ igtorres@pdi.ucm.es
}

\section{RESUMEN}

En el presente trabajo se aporta un análisis sobre el principio autonómico con base en la jurisprudencia del Tribunal Constitucional.

Palabras clave: Tribunal Constitucional, Estado Autonómico, Interpretación Constitucional.

\section{ABSTRACT}

In this essay we provide with an analysis of the autonomy principle based on Constitutional Case Law.

Keywords: Constitutional Court, Autonomous Communities State, Constitutional Interpretation.

\section{ZUSSAMENFASSUNG}

In der vorliegenden Arbeit wird eine Untersuchung zum Staatsprinzip der Autonomen Regionen Spaniens auf der Grundlage der Rechtsprechung des Verfassungsgerichts vorgenommen.

Schlüsselwörter: Verfassungsgericht, Staat der Autonomen Regionen, Verfassungsinterpretation.

SUMARIO: I. JUSTIFICACIÓN.-II. INTRODUCCIÓN.-III. ALGUNAS DECISIONES CLÁSICAS DEL TRIBUNAL CONSTITUCIONAL.-IV. LOS ÚLTIMOS DESARROLLOS: EL TC Y EL PROBLEMA AUTONÓMICO EN EL SIGLO XXI.-V. Y PUNTO Y FINAL. 


\section{JUSTIFICACIÓN}

Se reproduce aquí el texto que sirvió de base a una conferencia en la Scuola Normale de la Universidad de Pisa, revisado y actualizado. Ello explica la falta de aparato crítico y el tono, a veces divulgativo, del mismo. He pensado, sin embargo, que es mi trabajo que mejor homenajea a José Antonio Alonso de Antonio, siempre preocupado por los avatares de nuestro Estado Autonómico.

\section{INTRODUCCIÓN}

Quisiera discutir en esta intervención cual es el papel del Tribunal Constitucional en la construcción de nuestro Estado Autonómico, la particular versión española del Estado ¿regional o federal?; en todo caso, decididamente descentralizado.

Si bien mi objetivo principal es explicar los desarrollos más recientes del problema, creo que no puedo hacerlo sin una revisión de una historia que es ya en estos momentos una larga historia. Casi cuarenta años desde que en 1981 el Tribunal Constitucional dictara sus primeras decisiones en materia autonómica.

Es necesario recordar algunos datos importantes para comprender la situación española. Ante todo, un tópico; es decir, una afirmación en la que hay algo de verdad, pero que se puede también revisar críticamente. Me refiero a la idea de que la Constitución española no dice mucho o, por lo menos, no dice lo suficiente, sobre el régimen jurídico del Estado Autonómico. Esto es, en parte, verdad. Se ha dicho - lo he dicho también yo- que las reglas de la Constitución española no son sino una Disposición Transitoria, que no regulan verdaderamente el problema. El constituyente español, se afirma, no tenía claro el diseño final del Estado autonómico, y todo lo que ha hecho ha sido dar a los diversos actores políticos y constitucionales la posibilidad de, con la ayuda del famoso principio dispositivo, cerrar dicho Estado.

El ejemplo más claro de esta realidad es que en España la decisión sobre las competencias de las Comunidades Autónomas se delega a los Estatutos «regionales». Por supuesto, y esto es también claro, existen algunos límites en la Constitución. Por eso la Ley Orgánica del Tribunal Constitucional (en adelante, LOTC) habla del «bloque de constitucionalidad». 
Para decidir cuál es el ente que tiene la competencia se debe tener en cuenta no solo la Constitución, sino también los Estatutos de Autonomía, y otras leyes sobre el reparto de competencias.

Últimamente, sin embargo, creo que debemos revisar esta idea, porque de la misma se ha hecho una interpretación exagerada. Es cierto que nuestra Constitución no dice mucho, pero, en mi modo de ver las cosas, es cierto también que dice cosas muy importantes. Esta reflexión es fruto sobre todo de una, debo reconocer que no demasiado profunda, investigación sobre normativa comparada. Si uno lee los textos constitucionales de otros Estados «compuestos», puede ver cómo es habitual que las reglas no sean demasiado detalladas. En este contexto, la Constitución española no sería tan excepcional. Revisar, basándonos en esta reflexión, las reglas patrias, nos enseña que en nuestra norma suprema hay más cosas que las que hemos creído que había.

Pero es importante recordar este tópico porque es el que nos lleva a la base de esta charla. Si la Constitución no dice mucho sobre las reglas del Estado autonómico, el Tribunal Constitucional ha tenido como una de sus principales competencias la de dotar al sistema de las reglas que pudieran resolver los muchos problemas, competenciales y no competenciales, que se han presentado en todos estos años. El resultado es que se ha hablado, por ejemplo, de «Estado jurisdiccional autonómico», con un fórmula que se puede calificar de exagerada. En cierto sentido, el Tribunal ha sustituido al constituyente en la tarea de diseñar el Estado autonómico. Como esta es una realidad indiscutible hay que revisar la jurisprudencia constitucional española, porque si esa jurisprudencia es muy importante en todos los Estados federales/regionales, en España es simplemente decisiva. No se puede comprender bien el sistema si no se conocen bien las decisiones del TC, lo que, debo decir también, no es fácil.

\section{ALGUNAS DECISIONES CLÁSICAS DEL TRIBUNAL CONSTITUCIONAL}

En la introducción he querido recordar algunas verdades que son la base remota de este trabajo, verdades que obviamente no son absolutas, y pueden ser revisadas. Ahora conviene, antes de hablar sobre los problemas más recientes, hacer algún apunte sobre las más importantes decisiones, en esta materia, de la historia del TC. 
Y esto porque no es posible comprender la reacción del TC, a los desafíos del siglo XXI, sin conocer las líneas generales de su jurisprudencia.

Una primera afirmación, que puede derivarse del estudio de la jurisprudencia constitucional, es que el TC ha sido, durante muchos años, y creo que todavía lo es, moderadamente «proautonómico»; es decir, inclinado a resolver los problemas de nuestro Estado «compuesto» de un modo muy respetuoso con la idea del constituyente de construir un Estado en el cual la descentralización era un principio muy importante.

Se puede decir, por tanto, que en general el TC ha sido un Tribunal que ha querido consolidar aquellas decisiones del constituyente.

Está claro que no podemos referirnos a todas las sentencias del TC en las que se refleja esa idea, también porque son muchas. Después de las que resuelven recursos de amparo, las más numerosas son aquellas que deciden sobre los conflictos Estado-Comunidad Autónoma. Nuestro Estado autonómico, en sus aspectos competenciales, ha sido construido sentencia a sentencia; es un Estado «conflictual»; o, por lo menos, mucho más «conflictual» que aquellos de nuestro entorno.

Hemos visto en España una verdadera «batalla por las competencias», en la cual Estado y Comunidades Autónomas discuten ante el TC también los más nimios roces en el reparto de atribuciones.

Todos estos problemas, a veces exageradamente concretos, son la base de una compleja jurisprudencia que no podemos resumir aquí.

Lo que podemos hacer, sin embargo, es hablar de los momentos más importantes, las sentencias decisivas en la actividad del TC respecto a nuestro Estado regional/federal. He hecho una selección que creo que podría ilustrar su evolución. Curiosamente, solo dos sentencias.

La primera vez que el TC ha demostrado su inclinación en favor de dicho principio de autonomía ha sido en la STC 76/1983. Es interesante ver por qué lo ha hecho. Recordemos que en aquel caso el problema era que los partidos más importantes (UCD y PSOE), preocupados por la deriva del Estado autonómico, y después de un informe elaborado por administrativistas de las dos tendencias políticas, pero de la misma escuela universitaria, la del maestro García de Enterría, aprobaron en las Cortes una Ley Orgánica de Armonización del Proceso Autonómico (la llamada LOAPA), ley que contenía medidas para controlar un proceso que se pensaba era necesario reconducir.

No se hacía una reforma de la Constitución, sino que con dos instrumentos particulares del ordenamiento constitucional español (Ley Orgánica y Ley de Armonización) se quería alcanzar un resultado similar. 
Explicar todos los asuntos con los que se enfrenta la sentencia podría hacerlo solo en un tiempo del que no disponemos, y por eso, y porque creo que aquello que voy a subrayar es lo que explica los desarrollos posteriores, me voy a fijar solamente en el dato de que el TC ha dicho claramente que si bien otros actores constitucionales (las Cortes Generales, por ejemplo) pueden interpretar la Constitución, la última palabra, la decisión sobre el problema de si estamos ante una simple interpretación, o bien ante una verdadera reforma constitucional, corresponde a él mismo. Y, por esta razón, toda la operación de reconducir el proceso autonómico, como querían, debemos recordarlo, los dos partidos más importantes, se ha visto frenada por una declaración de inconstitucionalidad de los aspectos más importantes de la LOAPA.

Entonces el problema principal era que, según el TC, el legislador no podría hacer una interpretación de la Constitución que la reformase. Lo que hacía el Tribunal era recordar que el intérprete supremo de la ley fundamental era precisamente él. Es importante tener presente este dato por lo que veremos después.

La jurisprudencia en materia autonómica es, como ya he dicho, muy complicada, y por eso creo que, si queremos tener tiempo para comentar las decisiones más recientes, tenemos que hacer un esfuerzo de síntesis, y limitarnos a referirnos a otra sentencia para ilustrar ese «pro autonomismo» del Tribunal.

Hemos visto la STC 76/1983 dictada en los primeros momentos de andadura de nuestro Estado autonómico, y que frenó el intento de poner límites importantes al desarrollo de la descentralización. Los años ochenta del siglo xx habían visto los primeros pasos del Estado autonómico. En los noventa, con la reforma de casi todos los Estatutos de Autonomía, para ampliar las competencias de las Comunidades Autónomas, el proceso de devolución de poderes fue incluso más incisivo en el sentido de la profunda descentralización del Estado.

Haré referencia a una decisión de esta época, que es un segundo ejemplo claro de esta inclinación «proautonomista» del TC. Se trata de la STC 61/1997, sobre el problema de la supletoriedad del Derecho estatal. El art. 149.3 de la Constitución dispone en su último inciso que «el derecho estatal será, en todo caso, supletorio del derecho de las Comunidades Autónomas». Esta cláusula se interpretó en los primeros años de la historia de nuestro Estado autonómico en el sentido de que el Estado, valga la redundancia, podía producir Derecho, cuando las Comunidades Autónomas no lo hicieran, también en aquellas mate- 
rias de competencia autonómica, porque el Estado tenía una competencia legislativa general.

Pero en los años noventa han comenzado a darse algunas dudas al respecto. Antes de la sentencia en la que queremos detenernos, llegaron la STC 147/1991 y la STC 118/1996, que abrieron camino para cambiar la doctrina tradicional. Pero la «bomba», la sentencia criticada por casi todos, con la excepción de Jesús Leguina y yo mismo (debo decir que me encuentro en excelente compañía) es la STC 61/1997. Y esto porque, si bien en las otras sentencias los problemas de base no eran muy importantes, aquí se trataba de la Ley del Suelo nacional, un asunto de mucha trascendencia, también económica.

Para hacer un resumen del razonamiento del TC, diré que afirma que será derecho supletorio admisible solo aquel aprobado en el marco de una competencia atribuida claramente al Estado en la Constitución. Desde el momento en que, situación curiosa, todas las Comunidades Autónomas han (en sus Estatutos, y aplicando el art. 148.1.3 de la Constitución) previsto que tienen la competencia exclusiva en materia de ordenación del territorio, urbanismo, y vivienda, el Estado no tiene nada que decir en la materia, y, en consecuencia, no puede aprobar una Ley del Suelo nacional.

Este relato mío es, obviamente, una simplificación. Hay muchos otros problemas conexos en esta decisión, y en los desarrollos posteriores sobre el asunto, pero quería hablar aquí de esta sentencia porque es el ejemplo más claro de hasta qué punto ha llegado el TC en la defensa de la posición de las Comunidades Autónomas.

\section{LOS ÚLTIMOS DESARROLLOS: EL TC Y EL PROBLEMA AUTONÓMICO EN EL SIGLO XXI}

Las últimas decisiones del TC verdaderamente importantes sobre el Estado autonómico son las que se ocupan de las nuevas redacciones de los Estatutos catalán y valenciano; así como las que han dado respuesta a ciertos problemas planteados ya en siglo XXI.

En cuanto a la del Estatuto valenciano, STC 247/2007, lo más importante es que dice claramente que el TC considera que la inclusión de derechos en los Estatutos, como el derecho a gozar del agua en una cantidad que pueda satisfacer las necesidades de los valencianos (art. 17 del nuevo Estatuto), no es sino un ejemplo de formulación de normas orientativas de 
la actividad de los poderes públicos. De ninguna manera verdaderos derechos subjetivos fundamentales.

En el caso del Estatuto Catalán los problemas son más complicados. Nos hallamos ante el bloqueo de una reforma constitucional para responder a las demandas de mayor autonomía. No hubo, ni hay, acuerdo entre los principales partidos sobre la materia. Este obstáculo se intentó orillar mediante un Estatuto de Autonomía que interpretaba normas constitucionales, actividad no prohibida, pero ante la cual el TC tuvo que recordar contundentemente lo que ya sabemos, y lo que deduce de todo este trabajo. Él es el supremo intérprete de la Constitución. Lo dijo ya en el FJ 4 de la STC 247/2007, antes citada; y en otras (por ejemplo, FJ 4 de la STC 30/2011).

En aras de la brevedad debe bastarnos con citar un párrafo de la STC 31/2010. En su FJ 57 se dice, con contundencia, que «en su condición de intérprete supremo de la Constitución, el Tribunal Constitucional es el único competente para la definición auténtica —e indiscutible- de las categorías y principios constitucionales». Así de claro y sencillo. Como vemos, el círculo se cierra, y el TC repite, por si hubiera dudas, y en un contexto diferente, lo que había dicho ya en 1983.

\section{Y PUNTO Y FINAL}

La conclusión de estas reflexiones no puede ser sino la de que uno de los rasgos principales de la jurisprudencia autonómica del TC es el de que el Tribunal recuerda a todos que es el supremo intérprete de la Constitución, que tiene por encima solo al constituyente, y por debajo a todos los demás posibles intérpretes, afirmación esta que no por discutida por algunas doctrinas deja de ser cierta para la mayoría de nuestros operadores jurídicos. 